\title{
Two-year-old children but not domestic dogs understand communicative intentions without language,
} gestures, or gaze

Richard Moore, Bettina Mueller, Juliane Kaminski and Michael Tomasello

\begin{abstract}
Infants can see someone pointing to one of two buckets and infer that the toy they are seeking is hidden inside. Great apes do not succeed in this task, but, surprisingly, domestic dogs do. However, whether children and dogs understand these communicative acts in the same way is not yet known. To test this possibility, an experimenter did not point, look, or extend any part of her body towards either bucket, but instead lifted and shook one via a centrally pulled rope. She did this either intentionally or accidentally, and did or did not address her act to the subject using ostensive cues. Young 2-year-old children but not dogs understood the experimenter's act in intentional conditions. While ostensive pulling of the rope made no difference to children's success, it actually hindered dogs' performance. We conclude that while human children may be capable of inferring communicative intent from a wide variety actions, so long as these actions are performed intentionally, dogs are likely to be less flexible in this respect. Their understanding of communicative intention may be more dependent upon bodily markers of communicative intent, including gaze, orientation, extended limbs, and vocalizations. This may be because humans have come under selective pressure to develop skills for communicating with absent interlocutors - where bodily copresence is not possible.
\end{abstract}

\section{Introduction}

The ability to infer the communicative intentions of others enables individuals to engage in sophisticated and flexible acts of social coordination - even in the absence of language. As such, it has been hypothesized to explain not only human infants' acquisition of language, but also the ability of our early hominin ancestors to engage in the group hunting activities that allowed them to out-compete rivals in their ecological niche (Tomasello, 1999, 2008). These hunting abilities were boosted by the use of dogs, whose ability to understand human communicative intentions may be a consequence of both self-domestication and selective breeding (Coppinger \& Coppinger, 2001; Hare, Brown, Williamson \& Tomasello, 2002; Hare \& Tomasello, 2005). In the case of pre-verbal infants, dogs and our earliest ancestors, the ability to grasp the communicative intentions of others must rest on the recognition of non-verbal behavioural cues and features of action that trigger the inferential process by which recipients try to work out their interlocutors' messages. However, whether or not children and dogs rely upon the same cues to interpret communicative intent is not known. 
Young children can infer an experimenter's communicative intent across a variety of non-verbal tasks (Tomasello, Call \& Gluckman, 1997; Behne, Carpenter \& Tomasello, 2005; Senju \& Csibra, 2008; Leekam, Solomon \& Teoh, 2010; Moore, Liebal \& Tomasello, 2013). However, whereas children as young as 12 months are adept at using a point to determine the location where an experimenter had hidden a toy (Behne et al., 2005; Behne, Liszkowski, Carpenter \& Tomasello, 2012), only older children understand the same message when the speaker's sign is an arrow or a replica (Tomasello et al., 1997; Leekam et al., 2010), and only a minority of three year olds infer that message when an experimenter indicates the location by intentionally pressing a light switch (Moore et al., 2013). This suggests that children may start off with a limited repertoire of actions that they recognize as referential - perhaps bodily actions like gesture, directed gaze, or speech - and only later come to grasp that any action, including prosthetic devices like markers and lights, could be used as signs.

Domestic dogs (Canis familiaris) also excel at grasping human communicative intentions - outperforming our nearest living relatives, the non-human great apes, in a variety of socio-cognitive tasks that involve the understanding of pointing (Bräuer, Kaminski, Riedel, Call \& Tomasello, 2006; Kirchhofer, Zimmermann, Kaminski \& Tomasello, 2012). Not only do dogs understand index finger pointing (Miklósi, Polgárdi, Topál \& Csányi, 1998; Hare \& Tomasello, 1999); they also understand a variety of points produced with the human arm (Soproni, Miklósi, Topál \& Csányi, 2001) and even an extended leg (Udell, Giglio \& Wynne, 2008; Lakatos, Soproni, Dóka \& Miklósi, 2009; Kaminski, Nitzschner, Wobber, Tennie, Bräuer, Call \& Tomasello, 2011). However, they do not use cues provided by a pointing stick or a mechanical arm (Soproni et al., 2001; Udell et al., 2008) - and while they can use markers to locate hidden food, they interpret these markers less successfully when they do not see humans placing them (Udell et al., 2008; Riedel, Buttelmann, Call \& Tomasello, 2006; Wobber, Hare, Koler-Matznick, Wrangham \& Tomasello, 2009). They can also accurately infer communicative intentions when a human communicator asks them to fetch an object by holding up and showing a replica of that object, although they are less consistent when shown photographs of an object with similar goals (Kaminski, Tempelmann, Call \& Tomasello, 2009b).

A further line of research has investigated not just the varieties of signs that children and dogs understand, but also the conditions under which these signs are interpreted as communicative - potentially illuminating the cognitive mechanisms that support the cognition of intentional communication. Children of 14 months use an experimenter's gaze and her extended pointing finger to find a hidden toy when these are performed purposively and with sustained ostensive eye contact, but not when similar points are produced intentionally but un-purposively and with a distracted gaze (Behne et al., 2005). (Actions performed purposively are necessarily intentional. However, since actions can be performed deliberately but in pursuit of no goal, the converse does not hold.) This finding has been replicated for dogs (Kaminski, Schulz \& Tomasello, 2012). Furthermore, children do not take accidental actions to be communicative 
(Moore et al., 2013). While no study has explored whether dogs treat accidents as communicative, they have been found to follow a point more often when they had previously found food in a similar context suggesting that their interpretation of referential communication is determined not only by cues provided by humans, but also by contextual information that leads them to expect the presence of a referent (Scheider, Grassmann, Kaminski \& Tomasello, 2011).

Several studies also testify that a human's provision of ostensive signals - in the form of directed speech and ostensive gaze - facilitates the comprehension of communicative intentions in infants (Senju \& Csibra, 2008), toddlers (Leekam et al., 2010) - although see (Mooreet al., 2013) for a dissenting voice - and in dogs (Kaminski et al., 2012; Topál, Gergely, Erdőhegyi, Csibra \& Miklósi, 2009; Téglás, Gergely, Kupán, Miklósi \& Topál, 2012). These findings have led to the hypothesis that humans possess an adaptation for recognizing communicative intent, on the basis of which we are hardwired to interpret a variety of behavioural cues as indicating that their source has valuable information that she would like to communicate. This adaptation would facilitate social learning by processing automatically knowledge of when others are communicating, so that valuable cognitive resources can then be allocated to figuring what they are saying (Gergely \& Csibra, 2005; Gergely, Egyed \& Király, 2007; Csibra \& Gergely, 2009; Csibra, 2010). A similar pattern of sensitivity to ostensive behaviour in dogs has led some to hypothesize that this adaptation is shared by dogs (Téglás et al., 2012).

We sought to better understand whether there are clear limitations on children's and dogs' otherwise remarkable facility for understanding human communicative intent - by testing their ability to understand a referential act that lacked the bodily expressions of referential intent that they typically understand. We also sought to determine whether ostension plays the same role in human and dog understanding of communicative intent. If, for example, 2-year-old children turned out to be less reliant on the presence of ostensive cues than dogs, this might support the conclusion that subtly different cognitive processes are involved in the different species' understanding.

In an object choice paradigm, the intentions with which an experimenter indicated the location of a hidden prize (a toy for children, food for dogs) varied along two lines: whether the same action was performed intentionally, or by accident; and whether or not the action was performed ostensively - where the ostensive cues that we used were ostensive eye contact and directed speech. (Note that while ostensive cues may facilitate comprehension, it is not necessary that a speaker produce ostensive cues in order to enact communicative intent - so long as she has some expectation that her communicative intention could nonetheless be fulfilled (Grice, 1989). The experimenter could therefore be said to have acted with communicative intent even in the non-ostensive, intentional condition). 
The prize was hidden in one of two different buckets, which could be lifted and shaken by an experimenter by pulling on ropes attached to the buckets via a central pulley (see Figure $\underline{1}$ ). The use of this mechanism allowed us to (1) indicate the hiding place using the same action across conditions, and (2) to test comprehension of the communicative nature of the action independently of familiarity with the sign used. (Were a more familiar sign - like a point - used, participants might be more likely to treat it as communicative even when it was not performed with communicative intent.) In addition, so as not to provide further information about the location of the prize, the experimenter never looked, or oriented, or moved her body towards the hiding location.

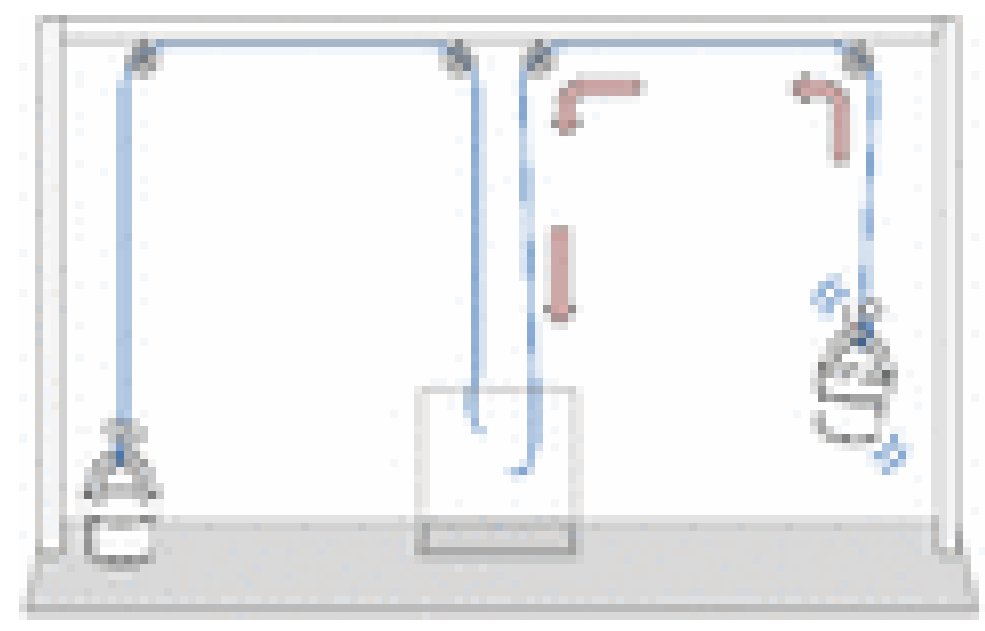

Figure 1. The rope and bucket mechanism. Food was hidden in one of two buckets, each of which could be lifted and shaken by pulling on one of two centrally hanging strings.

\section{Procedure and methods}

A pair of studies was conducted, using a procedure derived from a previous study on 3-year-old children, in which an electronic light-and-sound mechanism was used to indicate the location of a hidden toy (Moore et al., 2013). Changes were made to the apparatus to make the procedure more visually salient to younger children and non-human participants.

\section{Participants}

Our sample consisted of 61 children of $27 \pm 2$ months ( 31 girls, 30 boys; mean age $=27 ; 10$, range $=25$; 1 29;0) who were recruited from a database of parents who had volunteered their children to take part in child development studies, in a predominantly Caucasian medium-sized German city. Nine further children were tested but excluded from the final sample because they became distressed during testing, prompting the experimenter to abandon the test $(n=8)$, or because the child was deemed to be too inattentive during training for this phase to have been administered properly $(n=1)$.

In addition, 70 dogs were tested in a specially constructed dog cognition laboratory in the same mediumsized German city. Dogs were family pets living with their owners and were recruited after their owners 
responded to adverts looking for participants in dog cognition studies. The 70 dogs included in our analysis all completed the experimental task and training phase. Twenty-six further dogs were excluded from the final sample - because they were unable to be separated from their owners for the purpose of testing $(n=11)$, because they failed to complete the training phase $(n=8)$, or because they failed to complete the full number of test trials $(n=7)$.

\section{Experimental set-up: children}

\section{Materials and design}

For a novel sign, a rope-and-buckets mechanism consisting of two small plastic buckets hung $120 \mathrm{~cm}$ apart was used. Each bucket was lined with material (to make it silent) and covered with a fitted lid to which small bells were attached, to make the container both visually and aurally salient. Each bucket was tied to a rope and hung from a system of pulleys attached to a wooden frame (160 cm wide $\times 85 \mathrm{~cm}$ high). The tail end of each rope hung from the centre of the frame, behind a sheet of Perspex that was used to prevent child interference. The mechanism was placed upon a long, low testing table $(160 \times 38 \times 42 \mathrm{~cm})$. Various toys were hidden inside the buckets, including wooden cubes and plastic animals. After retrieval, children were encouraged to slide the toys into a 'pling machine' (a shoe box containing xylophone keys), in order to produce a 'pling' sound. In the training phase a yellow arrow $(24 \mathrm{~cm} \times 10 \mathrm{~cm})$ and a wooden pointing stick (35 cm long) were also used.

In a between-subjects design children each received four trials in one of four conditions in which the ostension and intentionality of the experimenter's action was varied: ostensive/intentional (boys $n=8$; girls $n=8$ ), non-ostensive/intentional (boys $n=7$; girls $n=8$ ); ostensive/accidental (boys $n=7$; girls $n=7$ ); and non-ostensive/accidental (boys $n=8$; girls $n=8$ ). In half the trials the toy was hidden in the left and in half in the right container, in counterbalanced order. Participants were tested by one of two female experimenters. The first tested the majority of children: ostensive/intentional (boys $n=6$; girls $n=6$ ), nonostensive/intentional (boys $n=5$; girls $n=6$ ); ostensive/accidental (boys $n=5$; girls $n=5$ ); and nonostensive/accidental (boys $n=6$; girls $n=6$ ). A second experimenter tested four further children in each condition (boys $n=2$; girls $n=2$ ), after the first experimenter became unavailable.

\section{Procedure}

Children were tested in a dedicated room in a child-testing laboratory. After a familiarization phase in which experimenter and child played with unrelated toys, the introduction phase started when the experimenter said, 'I know a game we can play. Let me show you something.' She led the child to a chair placed centrally and $110 \mathrm{~cm}$ in front of the testing table and removed a sheet covering the rope-andbuckets mechanism. Sitting behind the table, with two ropes hanging down in front of her, the 
experimenter explained to the child how the mechanism worked. She pulled on each rope in turn and said: 'When I pull this, this happens', while alternating her gaze between the child and the shaken bucket. The child was then invited to pull on the ropes herself. Finally, the experimenter demonstrated how the pling machine worked and encouraged the child to use it. This phase served to demonstrate the equipment to the child, prior to and independently from the test phase.

Since a novel cue was used in the main procedure, a training phase was administered at the same table to introduce participants to the hiding game and to help them grasp the possibility of using different signs for the same goal.

The experimenter called the child's attention, showed her the toy, and placed it in one of the containers in view of the child - before asking the child to retrieve the toy and place it into the pling machine. She did this once per side, in random order. In subsequent trials the experimenter concealed the toy in her hands and placed it discreetly into one box (random order, at most two consecutive trials per side). She then used one of three different signs to indicate its location (in fixed order): (1) an ipsilateral finger point, (2) an ipsilateral stick point, and (3) an ipsilateral arrow held vertically above the hiding place. After producing each sign for 3 seconds, in conjunction with ostensive eye contact and a smiling, engaged facial expression, the experimenter asked, 'Do you know where [it] is?', and encouraged the child to retrieve the toy and place it into the pling machine. Where children made incorrect choices, they were allowed to explore the empty box while the experimenter retrieved the toy from its hiding place, and showed them its actual location. Children were not rewarded for incorrect performance.

Children received each sign until they performed correctly in two consecutive trials, or until the maximum of six trials per sign was administered. Then the experimenter moved to the next sign, or to the main procedure. She signalled the end of the training phase by clapping her hands and saying 'That was a fun game!'

In the test phase, the experimenter hid the toy and then pulled on one rope repeatedly for 3 seconds, in order to lift and shake the bucket in which the toy had been hidden. This was done in one of four conditions. In the ostensive conditions, E engaged the child's eye contact, smiled, and said, 'And now ...' in an engaging way before pulling on the rope connected to the bucket in which the toy was hidden. While pulling the rope, E maintained eye contact and positive affect with the child. In the non-ostensive conditions, E did not engage the child's eye contact after hiding the toy, but studied the end of the rope in her hand as if inspecting it and said 'And now ...' as if speaking to herself. While pulling on the rope, E did not make eye contact with the child but kept looking down. In the intentional conditions, she pulled on the rope in a deliberate and confident manner. In the accidental conditions she shifted her weight, as if to 
make herself comfortable, and then 'accidentally' fell over, pulling on the rope in the process. She then sat back, startled, threw her hands in the air in mock surprise and said 'Oops!'

In all conditions, after releasing the rope, E paused, made eye contact with the child and asked playfully 'Do you know where [it] is?'

\section{Experimental set-up: dogs}

\section{Materials and design}

A ground-mounted system of pulleys and ropes was built similar to the one used with children. It was placed on a testing mat in the centre of which an experimenter kneeled, while looking towards the subject. Ropes were tied to small, sealable containers positioned $80 \mathrm{~cm}$ either side of the experimenter. These ropes joined to a system of pulleys attached to the ceiling, so that each container could be lifted and shaken by pulling on one of the pair of ropes hanging from pulleys above the experimenter's head. A Perspex panel was placed in front of the ends of the hanging ropes, to discourage dogs from playing with them.

In a between-subjects design, each dog was tested in one of five conditions by the same female experimenter. Four conditions matched those tested on children: ostensive/intentional ( $n=14$; males $n=8$; females $n=6$ ), non-ostensive/intentional ( $n=14$; males $n=7$; females $n=7)$, ostensive/accidental $(n=14$; males $n=6$; females $n=8$ ) and non-ostensive/accidental ( $n=14$; males $n=7$; females $n=7$ ). A further control condition ( $n=14$; males $n=7$; females $n=7$ ) was used to determine whether dogs' performance could be explained by a general lack of communicative competence. Here, in addition to providing the cues from the ostensive/intentional condition, the experimenter pointed to and gazed at the hiding-place.

\section{Procedure}

With minor differences, dogs were tested in the same procedure as children. In all conditions, and in the training phase, dogs were restrained $1.5 \mathrm{~m}$ in front of the centre of the testing table by a second experimenter. In a series of pre-training trials, food was hidden in full view of the dog. First E1 placed food in front of one bucket (random order, at most two consecutive trials per side). Once participants retrieved food successfully in two consecutive trials, this phase was repeated, but now food was concealed inside the container. After successful retrieval in two consecutive trials, participants proceeded to the training phase.

A slightly adapted version of the training phase was used for dogs - with the effect that they received more and more suitable training than children. (The change was made because in piloting we found both that dogs struggled to understand training sessions in which arrows and stick points were used, and that young 
children found the marker sign difficult. Since the training was supposed to encourage participants to think about alternative ways of indicating the location of a prize, it was therefore tailored to their performance.) Instead of three varieties of sign used between two and six times teach, dogs were trained using two different signs: an ostensive ipsilateral point, used without gaze alternation, and a marker placed on top of the hiding place, with a single gaze alternation between dog and box. The training phase ended when the dog found the food in four consecutive trials per sign.

In the training phase, the hiding process was concealed using a curtain placed between the dog and the experimenter, and which fully occluded the dog's view of the experimenter. The experimenter called the dog's name and made eye contact, while showing the dog the food that she would hide. Then E2 closed the curtain in front of the dog, concealing the hiding process. While the curtain remained closed, E1 opened each container in turn (to provide matching audio cues) and hid food in one. Once the food was hidden, E2 opened the curtain and E1 called the dog's attention by making eye contact and saying, '[Dog's name], look!', in an engaged tone of voice, before producing the sign.

In all trials in both training and test conditions the dog was able to eat any food that it found in the first box that it chose. When the wrong choice was made, E1 unscrewed the chosen container and allowed the dog to explore its contents. Subsequently, she retrieved and then stored away the food hidden in the other container. Participants were not rewarded for incorrect performance.

Following the training phase, E1 administered the test phase in one of five conditions. In all conditions, when the curtain was drawn following the hiding phase, E1 uttered the words, '[Dog's name], look!', before pulling on one rope repeatedly for 3 seconds. However, her tone of voice and gaze varied across conditions, as did the manner in which she pulled the rope. In ostensive conditions the command was given in a friendly, engaged tone of voice. In addition, E1 established eye contact with participants prior to speaking, and maintained this while the rope was pulled. In non-ostensive conditions her tone of voice was bored and disengaged, and she looked down towards her knees and hands, without establishing or maintaining eye contact. In intentional conditions, E1 knelt on the ground and pulled on the rope in a deliberate and confident manner. In the accidental conditions she placed her left hand on the Perspex panel, as if shifting her weight, before 'accidentally' falling forward and pulling the rope in the process. The intentional pointing condition was identical to the intentional/ostensive condition - except that E1 also produced an ipsilateral finger point and alternated her gaze between bucket and dog (see Figure $\underline{2}$ ). 


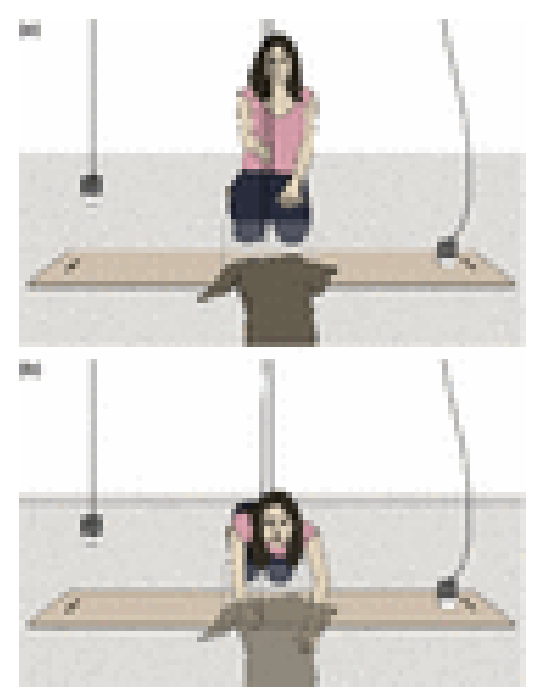

Figure 2. An illustration of the experimental set-up. The experimenter is shown in intentional/ostensive (top) and accidental/ostensive (bottom) test conditions.

\section{Scoring and reliability coding}

Responses were coded from videotape and counted as correct when participants chose the bucket containing the prize. Following Mooreet al. (2013), children were deemed to have chosen a container if they opened it (and so could see the object), picked it up (and so could feel the weight of the object), or if they indicated that they would like the experimenter to open it - for example, by pointing. Children did not count as choosing a bucket just by touching it - so if they touched one bucket and then opened the other, the latter action was counted. These criteria were adopted to best identify cases where children had made a clear decision. Occasionally children approached and touched one box, before turning and opening the other. We interpreted this behaviour as indecision and since touching one box (unlike lifting it) gave no information as to its contents, did not count such cases as choices. In addition, in several cases, shy children did not approach the experimenter but instead pointed. We interpreted these points as requests for the experimenter to open the box to which the child had pointed.

For children's choices to be counted as correct or incorrect, they had to be made within 30 seconds. If children did not make a choice promptly, they were counted as making 'no choice'. This happened in only two cases. All children successfully completed the four test trials.

Dogs were given 2 minutes to respond and were deemed to have chosen a location if they approached the box within a range of $10 \mathrm{~cm}$. If dogs did not respond within 2 minutes, the trial was rerun. If dogs failed to choose a cup in three consecutive trials, the test was cancelled and the subject excluded from the analysis. Only dogs who completed four trials were included in the dataset. 
To assess reliability, $20 \%$ of all trials ( 48 trials by children in total, from 3 children per condition; 56 trials featuring canine participants, from 2-3 participants per condition) were coded from tape by a second observer unaware of the experimental hypotheses and ignorant of the particular conditions. There was $100 \%$ agreement between coders about which containers both children and dogs chose.

For all participants, the sum of successful retrievals was calculated.

\section{Results}

In each of the conditions, participants' performance was compared to chance (correct choices, $n=2$ ). Children retrieved the toy above chance in the ostensive/intentional condition (one sample $t$-test: mean retrieval $=2.88, t(15)=2.782, p=.014$; success in $72 \%$ of trials), and in the non-ostensive/intentional condition (mean $=2.87, t(14)=3.166, p=.007 ; 72 \%$ success). In both accidental conditions children found the toy only at chance (ostensive accidental: mean $=2.21, t(13)=0.822, p=.426 ; 55 \%$ success; nonostensive accidental: mean $=1.88, t(15)=-0.808, p=.432 ; 47 \%$ success). (See Figure $\underline{3}$ ).

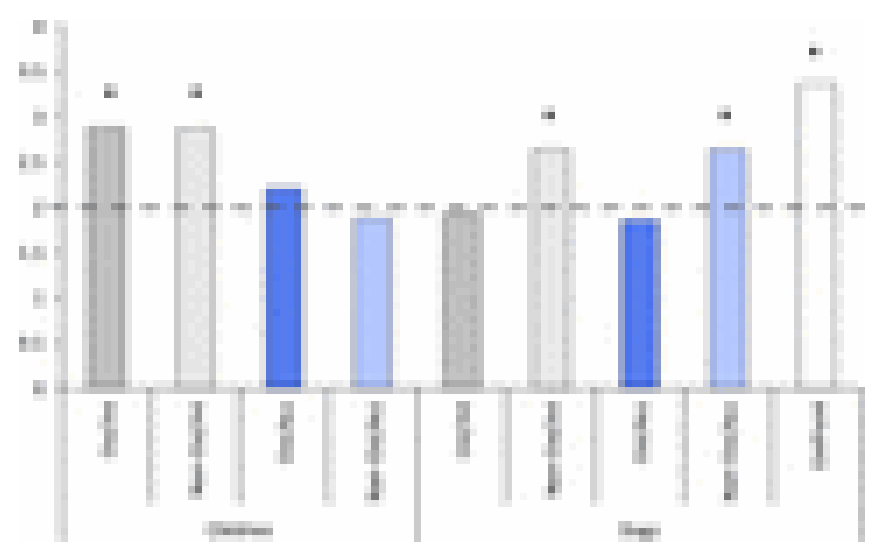

Figure 3. Mean success of child and canine participants at retrieving the hidden prize across conditions. Comparable conditions in children and dogs are marked with identical colour/pattern combinations. The dotted line indicates chance performance ( $n=2 / 4$ successful retrievals). Asterisks indicate performance above chance.

Dogs retrieved the food above chance in both non-ostensive conditions (non-ostensive/intentional: one sample $t$-test: mean retrieval $=2.64, t(13)=2.590, p=.022 ; 66 \%$ success; non-ostensive/accidental: mean $=$ $2.64, t(13)=2.386, p=.033 ; 66 \%$ success), but at chance in both ostensive conditions (ostensive/intentional: mean $=1.93, t(13)=0.291, p=.775 ; 48 \%$ success; ostensive accidental: mean $=$ $1.86, t(13)=0.520, p=.612 ; 47 \%$ success $)$. In addition, dogs also found the hidden food very significantly above chance in the ostensive pointing control condition (mean $=3.36, t(13)=6.032, p<.001 ; 84 \%$ success).

In addition to the comparisons to chance, we also ran a model combining all participants and testing for the effects of species, intentionality, ostension, sex, and the order in which trials were presented. Initially we 
used a Generalized Linear Mixed Model (Baayen, 2008) into which we included the order of presentation of trials (e.g. LRRL vs. RLLR) as a random effect. Since this variable appeared to have no significant effect of participants' performance (variance component $=0$ ) we subsequently collapsed it across the data. We then ran a combined Generalized Linear Model (McCullagh \& Nelder, 2008) to test for whether ostension, intention, and species affected the proportion of participants' correct responses. Coding as our response the number of successful and unsuccessful retrievals, we fitted our model with binomial error structure and logit link function. (Using $R$ one can model an individual's successful vs. unsuccessful responses as a proportion, using a binomial model.) As variables in the model we included ostension, intention and species, and all interactions between them (including the three-way ostension*intention*species interaction). To control for the effect of sex we included it as an additional predictor, and to test for the overall effect of ostension, intention and species we used a likelihood ratio test (Dobson, 2002) to compare the full model with a null model comprising only sex as a predictor (Forstmeier \& Schielzeth, 2011). We considered the effects of two-way interactions only if the three-way interaction was insignificant and so removed from the model; and we considered main effects only when they were not involved in significant two-way interactions (which were then themselves removed from the model). The removal of terms from the model was conditional on the comparison of the full model to the null one being significant. We did not compare nested models, dropping only the parameter of interest, since this strategy can generate false positive results (Forstmeier \& Schielzeth, 2011).

In order to better understand the results of the model with regard to the difference between humans and dogs, we also ran the corresponding models separately for each species. In both of these models, we included ostension and intentionality and their interaction as fixed effects in the initial full models. Furthermore, we included sex (fixed effect) and counterbalancing sequence (random effect) to control for their effects. Initially we ran GLMMs but when the counterbalancing sequence appeared insignificant we removed it and ran a GLM. The structure of the response and error link function was identical to the other models.

In the combined species model, there was a significant difference between the null model, which included only sex as a predictor variable, and the full model which also included ostension, intention, species, and their interactions (likelihood ratio test comparing full and null model: $c^{2}=21.87, d f=7, p=.003$ ). However, we found no significant three-way interaction (estimate $\pm S E=-0.39 \pm 0.77, z=-0.51, p=.614$ ), and also no two-way interaction between ostension and intention $(-0.16 \pm 0.39, z=-0.42, p=.672$; assessed from the model in which the non-significant three-way interaction had been removed). The other two interactions were significant (species*ostension: $0.97 \pm 0.39, z=2.52, p=.012$; species*intention:

$0.89 \pm 0.39, z=2.3, p=.022$ ), indicating that the effects of ostension and intention contributed to the performance of humans and dogs in different ways. 
In the model comprising human participants alone, there was a significant difference between the full model and the null model, which included only sex as a predictor variable (likelihood ratio test: $c^{2}=$ 12.79, $d f=3, p=.005)$. We found no interaction of intention*ostension (estimate $\pm S E=$ $-0.37+0.55, z=-0.67, p=.504)$. However, when this interaction was subsequently dropped from the model, we found a main effect of intention $(0.92+0.27, z=3.35, p=.001)$, although not of ostension $(0.20+0.27, z=0.73, p=.468)$.

For dogs, a full model comprising ostension, intention, their interaction, and sex as predictors was also significantly better than a null model comprising sex alone (likelihood ratio test: $c^{2}=8.10, d f=3, p=.044$ ). (Data from the pointing control condition were not included in this analysis.) We found no intention*ostension interaction (estimate $S E=0.05+0.55, z=0.08, p=.94$ ). When this interaction was subsequently dropped from the model, we found a main effect of ostension $(-0.78+0.28, z=-2.82, p=.005)$ but no effect of intentionality $(0.02+0.28, z=0.09, p=.931)$.

\section{Discussion}

To solve this task, participants had to take the experimenter's pulling the rope to be relevant to their hiding and finding game, and revelatory of her intention to indicate the location of the prize. Children determined this above chance in both intentional conditions, but neither accidental condition. The presence of ostensive cues, in the form of ostensive eye contact and directed speech, made no difference to their success. By contrast, dogs found the prize above chance only in non-ostensive conditions. Intentional performance made no difference to their success.

These findings suggest that children were not searching for the toy because of the greater salience of the shaken bucket. Rather, in the intentional conditions, they took the experimenter's actions to be revelatory of communicative intent - or, at least, were willing to treat her behaviour as if it were revelatory of communicative intent. (The latter may have occurred in the intentional, non-ostensive condition - where the communicative nature of E1's action was less evident.) Consequently, in intentional conditions they searched in the location that the experimenter's action indicated. Children also assumed that unintentional actions are not communicative, such that the shaking of one box in the accidental conditions was not an expression of communicative intent. In these conditions they did not use the experimenter's actions as a guide, and located the toy only at chance. By contrast, dogs' failure to use intentional performance of the sign as a cue suggests that - at least in this experimental set-up - they were not tracking the experimenter's communicative intent, but only tracking the salience of one location relative to the other. Nonetheless, in the pointing control condition they did find the food above chance. Their performance in 
experimental conditions was therefore not explained by a general inability to track human communicative intent.

Ostensive performance actually undermined dogs' success. This may be because, at least in this task, dogs were using a non-communicative strategy to locate the food - and searching on the basis of the salience of the hiding place relative to the other. In the ostensive conditions the experimenter's ostensive gaze preoccupied their attention, such that they failed to register the shaking of the hiding location. This finding is consistent with evidence that ostensive behaviour by a human can actually distract dogs when they are in a social learning situation - by diverting their attention from potentially rewarding sources of information (Range, Heucke, Gruber, Konz, Huber \& Virányi, 2009).

In contrast to dogs, ostensive performance played no significant role in children's recognition of communicative intent. This replicates a recent finding that the presence of ostensive cues is at least sometimes unnecessary for comprehending communicative intent, even where highly novel signs are used (Moore et al., 2013). It also extends this finding by identifying the ability to do without ostension in children of 27 months -9 months younger than those previously tested.

One function for ostensive cues that might be predicted by proponents of the sufficiency claim (e.g. Csibra, 2010) would be using the presence of ostension to infer that a novel sign was being used with communicative intent. Given the absence of an effect of ostension in children, it seems unlikely that they were using ostension in this way. Rather, they relied on other cues to infer the communicative nature of the sign. It may be that where communicative interaction has already been established, or where a context of ongoing interaction generates the expectation that communicative behaviour might be forthcoming, children are willing to treat acts as potentially communicative even in the absence of ostensive cues - so long as they are performed intentionally. Such contexts might explain the superfluity of ostensive cues in the present study, given the inclusion of a warm-up game in which the experimenter made evident her intention to help participants find the hidden toy.

Our findings are not inconsistent with the claim that ostensive cues suffice to indicate communicative intent - both for children (Gergely \& Csibra, 2005; Gergely et al., 2007; Csibra \& Gergely, 2009; Csibra, 2010) and dogs (Téglás et al., 2012). It may be that children in ostensive conditions initially interpreted ostensive performances as communicative acts, and only subsequently reasoned that ostensive but accidental acts could not be communicative, or that non-ostensive acts might nonetheless be communicative. In ostensive conditions, dogs might also have expected a communicative act, but simply failed to recognize the experimenter's rope-pulling as a sign. Perhaps they were waiting for a point that never came. Nonetheless, our findings do not support the claim that ostensive cues suffice to indicate 
communicative intent, since they are consistent with weaker claims - for example, that ostensive cues function only to solicit attention (Moore et al., 2013; Moore, 2014). Moreover, the findings show that children are less dependent on ostensive cues for interpreting communication than might be supposed.

There may be several possible explanations for why dogs but not children found this study difficult.

One possibility is that canine subjects failed to understand the equipment used. Some evidence suggests that while dogs do understand the basics of pulling on a string to obtain a reward that is attached to the string (the 'connectivity principle'), when strings are arranged such that the end of an un-baited string is nearer to the reward than the end of the baited string, dogs choose the nearer, un-baited string (Osthaus, Lea \& Slater, 2005; Range, Möslinger \& Virányi, 2012; Riemer, Müller, Range \& Huber, 2014). Given their rudimentary understanding of connectivity, it may be that dogs in this study simply failed to understand that the experimenter's behaviour caused the shaking of the bucket. While this is possible, we do not think it likely. First, all of the above studies support the conclusion that dogs do understand connectivity in simple causal cognition tasks, as do further studies (Mersmann, Tomasello, Call, Kaminski \& Taborsky, 2011; Range, Hentrup \& Virányi, 2011). Connectivity and proximity were not confounded in our apparatus making our task simpler than those in which dogs perform poorly. In addition, dogs did perform above chance in three out of five conditions, including the intentional pointing control - suggesting that they did take the shaking of one bucket to be relevant to the task of finding the food. Nonetheless, we acknowledge that we cannot conclusively rule out this possibility. (In future research dogs' ability to infer communicative intent from an act of rope pulling could be confirmed or disconfirmed using a simpler mechanism, less dependent on their understanding of connectivity.) In the meantime, in what follows we focus primarily on the implications of children's positive performance for their understanding of communicative intent.

An alternative explanation of the data is that what drives recognition of communicative intent is not ostension, but the knowledge that a particular type of action could be used as a sign; and that children but not dogs were able to grasp that a rope can be pulled with communicative intent (that is, that a rope-pull can be used as a sign). Since children grasped this potential, they tracked intentional performance of the sign and inferred that the experimenter was performing the action in order to indicate the toy's location. By contrast, dogs may simply have failed to grasp that the experimenter was acting with communicative intent, and so tracked food using a non-communicative strategy. Children's success in this task shows that they possess a flexible understanding of the range of actions that can be performed with communicative intent - perhaps even knowing that any action could, in principle, be performed communicatively. Dogs may not share this insight - perhaps recognizing only a range of points, vocalizations and iconic signs and markers as potentially communicative acts (at least, so long as the icons and markers are held by a human). 
What would be the adaptive value of recognizing actions as potentially communicative, even in the absence of ostension and 'embodied' referential cues like gaze and extended limbs? One possibility is that this reflects an adaptive ability for communication with absent others.

Using gaze and limbs to direct others in space, and eye contact to address communicative acts to an intended audience, is an excellent way to coordinate with others who remain in visual contact. Extended limbs and orientation also make for a repertoire of signs that is easily understood as referential because they naturally express an agent's interest in or preoccupation with the feature of the world towards which she is looking or pointing (Bar-On, 2013; Moore, 2013). This makes such signs particularly easy to interpret. They are therefore likely to have been particularly important for our ancestors in coordinating their movements with others in the context of cooperative activity (Tomasello, 2008), such as hunting and herding interactions.

Some of these interactions are likely to have included dogs in the process of being domesticated, leading to selective pressure for them to understand at least a limited repertoire of signs that would enable their human masters to coordinate their movements over medium distances, and in the present moment. In these interactions, our ancestors could have used their limbs, bodies and gaze, not to mention voice projection, to direct the dog's movements (Wobber \& Kaminski, 2011; Kaminski \& Nitzschner, 2013; Rossano, Nitzschner \& Tomasello, 2014). This is consistent with existing evidence that dogs interpret the movements of a variety of extended human - but not artificial - limbs as expressive of communicative intent. (Crucially, when dogs understand iconic signs and markers, they were held up and shown to dogs by humans; they were not understood in the absence of their owners (Udell et al., 2008; Riedel et al., 2006; Wobber et al., 2009; Kaminski et al., 2009b).) It is also consistent with the finding that where familiar signs are used, whether or not they are performed purposively makes a difference to whether dogs treat them as communicative (Kaminski et al., 2012).

Such 'embodied' signs and vocalizations would be much less effective when interlocutors were not (in some sense) co-present. As they engaged in spatio-temporally extended cooperative activities, our ancestors came under pressure to plan and communicate about activities that were both physically and temporally distant. These pressures likely resulted in selection for abilities that reduced dependence on directed gaze and the extension of limbs - such that even early in ontogeny children can see 'disembodied' signs as revelatory of a speaker's message.

In their earliest iterations, these signs might have been marks left by group members to carry messages for others lagging behind. In such cases, ostensive cues could not be usefully employed, and varieties of 'disembodied' sign would also be needed to show others where to go. Here markers of intentional 
production are likely to have been key to the possibility of a sign's being appropriately interpreted - as a means, for example, of disambiguating a deliberately carved arrow from mere scratches on a tree, and so marking that arrow as a potential bearer of a speaker's message. Humans might therefore have developed skills for identifying communicative intent across a range of contexts - skills for which dogs had no need. This is not to downplay dogs' exceptional skills for understanding human communication. They have been shown to be capable of some highly impressive inferences about what others could be referring to, when these intentions are articulated vocally (Kaminski, Call \& Fischer, 2004; Kaminski, Bräuer, Call \& Tomasello, 2009a; Kaminski et al., 2009b) and through familiar gestures like points (Scheider et al.,2011). Nonetheless, the variety of actions that dogs recognize as potential signs may be limited even in comparison to 2-year-old children.

Future studies should seek to confirm or disconfirm this hypothesis - not least, perhaps, by trying to replicate the current study using a system of signs less dependent on dogs' understanding of connectivity.

\section{Acknowledegments}

The authors would like to thank Katja Schönefeld, Kerstin Esau and Christian Biermann, who tested the children in this study, and the research assistant Susanne Mauritz. In addition, Roger Mundry provided invaluable statistical advice, Marike Schreiber made the illustrations in Figure $\underline{1}$, and Gloria Wallmeier carried out reliability coding. Thom Scott-Phillips, Anna Strasser, and two anonymous reviewers provided very helpful comments on the manuscript.

\section{References}

Baayen, R. (2008). Analyzing linguistic data. Cambridge: Cambridge University Press.

Bar-On, D. (2013). Origins of communication: must we 'go Gricean'? Mind \& Language, 28 (3), 342-375.

Behne, T., Carpenter, M., \& Tomasello, M. (2005). One-year-olds comprehend the communicative intentions behind gestures in a hiding game. Developmental Science, 8 (6), 492-499.

Behne, T., Liszkowski, U., Carpenter, M., \& Tomasello, M. (2012). Twelve-month-olds' comprehension and production of pointing. British Journal of Developmental Psychology, 30, 359-375.

Bräuer, J., Kaminski, J., Riedel, J., Call, J., \& Tomasello, M. (2006). Making inferences about the location of hidden food: Social dog, causal ape. Journal of Comparative Psychology, 120 (1), 38-47.

Coppinger, R., \& Coppinger, L. (2001). Dogs: A startling new understanding of canine origin, behavior and evolution. New York: Scribner.

Csibra, G. (2010). Recognizing communicative intentions in infancy. Mind \& Language, 25 (2), 141-168.

Csibra, G., \& Gergely, G. (2009). Natural pedagogy. Trends in Cognitive Sciences, 13 (4), 148-153. 
Dobson, A. (2002). An introduction to generalized linear models. Boca Raton, FL: Chapman and Hall/CRC Press.

Forstmeier, W., \& Schielzeth, H. (2011). Cryptic multiple hypotheses testing in linear models: overestimated effect sizes and the winner's curse. Behavioural Ecology and Sociobiology, 65, 47-55.

Gergely, G., \& Csibra, G. (2005). The social construction of the cultural mind: imitative learning as a mechanism of human pedagogy. Interaction Studies, 6 (3), 463-481.

Gergely, G., Egyed, K., \& Király, I. (2007). On pedagogy. Developmental Science, 10 (1), 139-146.

Grice, P. (1989). Studies in the way of words. London: Harvard University Press.

Hare, B., Brown, M., Williamson, C., \& Tomasello, M. (2002). The domestication of social cognition in dogs. Science, 298, 1634-1636.

Hare, B., \& Tomasello, M. (1999). Domestic dogs (Canis familiaris) use human and conspecific social cues to locate hidden food. Journal of Comparative Psychology, 113 (2), 173-177.

Hare, B., \& Tomasello, M. (2005). Human-like social skills in dogs? Trends in Cognitive Sciences, 9, 439-444. Kaminski, J., Bräuer, J., Call, J., \& Tomasello, M. (2009a). Domestic dogs are sensitive to a human's perspective. Behaviour, 146 (7), 979-998.

Kaminski, J., Call, J., \& Fischer, J. (2004). Word learning in a domestic dog: evidence for 'fast mapping'. Science, 304 (5677), 1682-1683.

Kaminski, J., \& Nitzschner, M. (2013). Do dogs get the point? A review of dog-human communication ability. Learning and Motivation, 44 (4), 294-302.

Kaminski, J., Nitzschner, M., Wobber, V., Tennie, C., Bräuer, J., Call, J., \& Tomasello, M. (2011). Do dogs distinguish rational from irrational acts? Animal Behaviour, 81 (1), 195-203.

Kaminski, J., Schulz, L., \& Tomasello, M. (2012). How dogs know when communication is intended for them. Developmental Science, 15 (2), 222-232.

Kaminski, J., Tempelmann, S., Call, J., \& Tomasello, M. (2009b). Domestic dogs comprehend human communication with iconic signs. Developmental Science, 12 (6), 831-837.

Kirchhofer, K., Zimmermann, F., Kaminski, J., \& Tomasello, M. (2012). Dogs (Canis familiaris), but not chimpanzees (Pan troglodytes) understand imperative pointing. PLoS ONE, 7 (2), e30913.

Lakatos, G., Soproni, K., Dóka, A., \& Miklósi, Á. (2009). A comparative approach to dogs' (Canis familiaris) and human infants' comprehension of various forms of pointing gestures. Animal Cognition, 12, 621-631. Leekam, S.R., Solomon, T.L., \& Teoh, Y.-S. (2010). Adults' social cues facilitate young children's use of signs and symbols. Developmental Science, 13 (1), 108-119.

McCullagh, P., \& Nelder, J.A. (2008). Generalized linear models. London: Chapman and Hall.

Mersmann, D., Tomasello, M., Call, J., Kaminski, J., \& Taborsky, M. (2011). Simple mechanisms can explain social learning in domestic dogs (Canis familiaris). Ethology, 117, 1-16.

Miklósi, Á., Polgárdi, R., Topál, J., \& Csányi, V. (1998). Use of experimenter-given cues in dogs. Animal Cognition, 1, 113-121. 
Moore, R. (2013). Evidence and interpretation in great ape gestural communication. Humana. Mente, Journal of Philosophical Studies, 24, 27-51.

Moore, R. (2014). Ontogenetic constraints on Grice's theory of communication. In D. Matthews (Ed.), Pragmatic development in first language acqusition (pp. 87-104). Amsterdam: John Benjamins.

Moore, R., Liebal, K., \& Tomasello, M. (2013). Three-year-olds understand communicative intentions without language, gestures, or gaze. Interaction Studies, 14 (1), 62-80.

Osthaus, B., Lea, S.E., \& Slater, A.M. (2005). Dogs (Canis lupus familiaris) fail to show understanding of means-end connections in a string-pulling task. Animal Cognition, 8 (1), 37-47.

Range, F., Hentrup, M., \& Virányi, Z. (2011). Dogs are able to solve a means-end task. Animal Cognition, 14, 575-583.

Range, F., Heucke, S., Gruber, C., Konz, A., Huber, L., \& Virányi, Z. (2009). The effect of ostensive cues on dogs' performance in a manipulative social learning task. Applied Animal Behaviour Sciences, 120 (3), 170178.

Range, F., Möslinger, H., \& Virányi, Z. (2012). Domestication has not affected the understanding of meansend connections in dogs. Animal Cognition, 15, 597-607.

Riedel, J., Buttelmann, D., Call, J., \& Tomasello, M. (2006). Domestic dogs (Canis familiaris) use a physical marker to locate hidden food. Animal Cognition, 9, 27-35.

Riemer, S., Müller, C., Range, F., \& Huber, L. (2014). Dogs (Canis familiaris) can learn to attend to connectivity in string pulling tasks. Journal of Comparative Psychology, 128 (1), 31-39.

Rossano, F., Nitzschner, M., \& Tomasello, M. (2014). Domestic dogs and puppies can use human voice direction referentially. Proceedings of the Royal Society of London - Series B.

http://dx.doi.org/10.1098/rspb.2013.3201

Scheider, L., Grassmann, S., Kaminski, J., \& Tomasello, M. (2011). Domestic dogs use contextual information and tone of voice when following a human pointing gesture. PLOS ONE, 6 (7), e21676.

Senju, A., \& Csibra, G. (2008). Gaze following in human infants depends on communicative signals. Current Biology, 18, 668-671.

Soproni, K., Miklósi, Á., Topál, J., \& Csányi, V. (2001). Comprehension of human communicative signs in pet dogs (Canis familiaris). Journal of Comparative Psychology, 115 (1), 122-126.

Téglás, E., Gergely, A., Kupán, K., Miklósi, Á., \& Topál, J. (2012). Dogs' gaze following is tuned to human communicative signals. Current Biology, 22 (3), 209-212.

Tomasello, M. (1999). The cultural origins of human cognition. London: Harvard University Press.

Tomasello, M. (2008). Origins of human communication. Cambridge, MA: MIT Press.

Tomasello, M., Call, J., \& Gluckman, A. (1997). Comprehension of novel communicative signs by apes and human children. Child Development, 68 (6), 1067-1080.

Topál, J., Gergely, G., Erdőhegyi, Á., Csibra, G., \& Miklósi, Á. (2009). Differential sensitivity to human communication in dogs, wolves, and human infants. Science, 325, 1269-1272. 
Udell, M., Giglio, R., \& Wynne, C. (2008). Domestic dogs (Canis familiaris) use human gestures but not nonhuman tokens to find hidden food. Journal of Comparative Psychology, 122 (1), 84-93.

Wobber, V., Hare, B., Koler-Matznick, J., Wrangham, R., \& Tomasello, M. (2009). Evidence for two waves of selection on the social skills of dogs. Interaction Studies, 10 (2), 206-224.

Wobber, V., \& Kaminski, J. (2011). What do dogs understand about human communicative signals? A novel synthesis. In V. DeGiovine (Ed.), Dogs: Biology, behavior, and health disorders (pp. 93-109). New York: Nova Science Publishers. 